\title{
"Retraction: Asset allocation in equity, fixed-income and cryptocurrency on the base of individual risk sentiment"
}

\author{
Alexey Mikhaylov (D http://orcid.org/0000-0003-2478-0307 \\ R https:/publons.com/researcher/2444707/alexey-mikhaylov/ \\ Natalia Sokolinskaya iD http://orcid.org/0000-0002-4731-722X \\ Evgeniy Lopatin iD http://orcid.org/0000-0001-6858-5170
}

AUTHORS

Alexey Mikhaylov, Natalia Sokolinskaya and Evgeniy Lopatin (2019). Retraction:

ARTICLE INFO Asset allocation in equity, fixed-income and cryptocurrency on the base of individual risk sentiment. Investment Management and Financial Innovations, 16(2), 171-181. doi:10.21511/imfi.16(2).2019.15

DOI http://dx.doi.org/10.21511/imfi.16(2).2019.15

RELEASED ON Thursday, 06 June 2019

RECEIVED ON

Tuesday, 16 April 2019

ACCEPTED ON

Friday, 31 May 2019

\section{(c)) EY}

LICENSE

This work is licensed under a Creative Commons Attribution 4.0 International License

JOURNAL Investment Management and Financial Innovations"

ISSN PRINT $1810-4967$

ISSN ONLINE $1812-9358$

PUBLISHER

LLC "Consulting Publishing Company "Business Perspectives"

FOUNDER

LLC "Consulting Publishing Company "Business Perspectives"

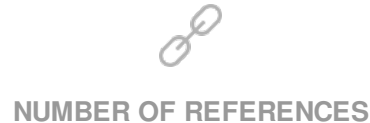

32
NUMBER OF FIGURES

0
NUMBER OF TABLES

6

(C) The author(s) 2022. This publication is an open access article. 


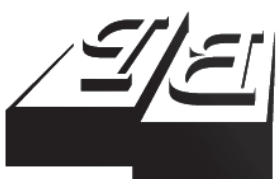

BUSINESS PERSPECTIVES

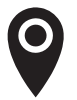

LLC "CPC "Business Perspectives" Hryhorii Skovoroda lane, 10, Sumy, 40022, Ukraine

www.businessperspectives.org

Received on: $16^{\text {th }}$ of April, 2019 Accepted on: $31^{\text {st }}$ of May, 2019

(C) Alexey Mikhaylov, Natalia Sokolinskaya, Evgeny Lopatin, 2019

Alexey Mikhaylov, Ph.D., Department of Financial Markets and Banks, Financial University under the Government of the Russian Federation, Moscow, Russia.

Natalia Sokolinskaya, Ph.D., Professor, Department of Financial Markets and Banks, Financial University under the Government of the Russian Federation, Moscow, Russia.

Evgeny Lopatin, Laborant, British College of Banking \& Finance, London, United Kingdom.

\section{(ㄷ) (i)}

This is an Open Access article, distributed under the terms of the Creative Commons Attribution 4.0 International license, which permits unrestricted re-use, distribution, and reproduction in any medium, provided the original work is properly cited.
Alexey Mikhaylov (Russia), Natalia Sokolinskaya (Russia),

Evgeny Lopatin (United Kingdom)

\section{ASSET ALLOCATION IN EQUITY, FIXED-INCOME AND CRYPTOCURRENCY ON THE BASE OF INDIVIDUAL RISK SENTIMENT}

\begin{abstract}
The major problem of investment process is individual risk sentiment. Understanding how personal characteristics affect risk attitudes is a significant question. This paper develops the Merton risk model in the context of Modern Portfolio Theory. The statistical methods are analysis of variance (ANOVA) and Mann-Whitney statistic tests for an individual agent with an infinite continuous horizon of investment. Research in this field has produced various perplexing results. It is the first research about risk sentiment of Russian investors. The authors study individuals in Russia and factors for decision making of individual investors such as age, field of work, salary, salary stability, income, risk sentiment, savings. The individuals are of special interest for several reasons. Also, 5-years exchange traded funds (ETF) and bitcoin performance were analyzed to find potential risks. Based on statistics of risk sentiment and ETF performance, it is found that, in general, the high-risk investors have lower income and lower age. The paper suggests that individual risk in young age often becomes more willing, but older individual investor become less risk-seeking. The authors propose the model for choosing optimal asset allocation of exchange-traded funds.
\end{abstract}

\section{Keywords risk attitude, profit perception, loss perception, decision \\ JEL Classification making, asset allocation, Modern Portfolio Theory}

\section{INTRODUCTION}

Everyone has his or her own risk appetite or risk profile. It determines which investment instruments are best suited for capital formation, and what yield it can get in the end.

The attitude to risks is the main investment indicator that determines how and where a person needs to invest his savings. The tendency to risk affects the investment strategy - what kind of assets a person is comfortable to invest in?

There are different classifications of risk profiles, in other words, types of investors according to the degree of risk. All of them represent a range of relatively risky and conservative people. The result of risk profiling is expressed in assessing the client's risk readiness, most often on a three-point (low, medium, high) or five-point (low, moderate-low, medium, moderate-high, high) scale, and for each level of risk there is usually offered a choice of several suitable solutions. For example, low level of risk - conservative portfolio (bonds, strategies with protection), high level - aggressive portfolio (stocks, commodities, gold). 
Regardless of what you are an investor, there are a number of recommendations that should be used, and a number of pitfalls that should be avoided.

Another interesting fact is that under the influence of emotions and nerves, which are not uncommon in stock investing, the attitude to risk can change briefly. In this case, experts advise to temper the fervor, wait until the emotions subside, since they are not the best adviser for an effective investor.

From the point of view of risk appetite, it is convenient and effective to form your investment portfolio in an automated mode. The fact is that investment advisors and portfolio managers will still offer their priority instruments, according to their subjective opinion. In the automatic system, the investment portfolio will be formed objectively for a particular person and his expectations and risk appetite.

ETF usually propose to identify the risk profile of each client - commonly on a scale that runs between "risk aversion" and "risk seeking":

- risk-averse;

- normal risk sentiment;

- high risk sentiment;

- $\quad$ very high risk sentiment.

\section{LITERATURE REVIEW}

A central point of behavior theory and its successor is that investors are not consistently riskaverse (Kahneman \& Tversky, 1979; Tversky \& Kahneman, 1981; Tversky \& Kahneman, 1992).

Thaler and Johnson (1990) find that people tend to take higher risk immediately following a previous gain. It is supported by the further laboratory experiments of Battalio et al. (1990). Franken et al. (2006) study the game theory point in Bechara et al. (2000).

Imas (2016) shows that many individuals with paper losses accept more risk but that, once a loss is realized, they take less risk. Imas also replicates selected findings of Shiv et al. (2005), Weber and Zuchel (2005), and Langer and Weber (2008).

Weber et al. (2012) showed the behavior of British investors to study their risk-taking aspects during the 2008 financial crisis. Frino et al. (2008) studied the behavior of futures investors in Australia. Liu et al. (2010) looks at investors in the Taiwan Futures Exchange.

It is hardly to tell what defines a risk of a specific investor at oil market (Mikhaylov, 2018a; Mikhaylov, 2018b).
As a rule, risk appetite strengthens with a higher level of education (Riley \& Chow, 1992; Halek \& Eisenhauer, 2001; Hartog et al., 2002).

Females are more worry about safety (Bajtelsmit \& Bernasek, 1996), while males are more risky than female (Eckel \& Grossman, 2008).

The experiments of Nosić and Weber (2010) covered aggressive risk-taking. Merkle (2017) reports significant empirical findings.

Keasey and Moon (1996), Ackert et al. (2006) show that the decline in the stock market may bring better asset allocation yield than the formation of a portfolio based on the traditional capital asset pricing model (CAPM).

Here, we investigate the degree to which attributes of individual investors influence subsequent asset allocation choices. We can use at the risk behavior of investors in exchange-traded funds (ETF) in each country. ETF prices, however, were a source of clear financial information that could be useful. Currencies of commodity-producing countries, such as Australia and Canada, are correlated with commodity prices (Hsu \& Chow, 2013).

Barber and Odean (2000) proposed construction of currency portfolios based on the forecasted 
yield in fixed prices. The risk of the stock market is not related to emerging currency portfolios.

There is a risk sentiment of the carry trade strategy, trade, which is associated with individual income. This price risk in commodity markets is linked to the currencies of developing countries (Eckel \& Grossman, 2008; Lusardi \& Mitchell, 2008).

Thus, commodity prices can affect the profitability of currency trading. We find that important risk factors for the profitability of ETF transactions. Many researches (Schubert et al., 1999; Croson \& Gneezy, 2009) relate risk sentiment to future currency returns, but we focus on the relationship between risk sentiment and individual risk factors.

This result is supported by Powell and Ansic (1997), Byrnes et al. (1999) who explain the strong correlation between individual risk sentiment and factors of age and income.

That is enough literature review to begin methods overview.

\section{METHOD AND DATA}

To quantify the investment qualities of individual investors, depending on the ETF management strategy, it is necessary to study the typology of ETF investors. We use results of the Russia Longitudinal Monitoring Survey - Higher School of Economics (RLMS-HSE) in 2017 year/footnote ("Russia Longitudinal Monitoring survey, RLMS-HSE", conducted by the National Research University Higher School of Economics and ZAO "Demoscope" together with Carolina Population Center, University of North Carolina at Chapel Hill and the Institute of Sociology RAS https:// www.hse.ru/en/rlms/downloads).

This dataset includes factors for decision making of 1,542 individual investors such as age, field of work, salary, salary stability, income, risk sentiment, savings. We use average RUB/USD rate in 2017. It is equal 58,13 RUB to convert incomes and savings into USD.

We also use data about all 708 US Equity ETF and 106 US Bond ETF from Thomson Reuters
Datastream for last 5 years (from 2013 till 2017). We found average performance and risk ratios for all US Equity and Bond ETF in order to make optimal asset allocation for different risk profiles.

Now in Russia the segment of the exchange traded funds is developing so quickly. The customers of Russian banks typically have savings. We have a survey of Russian population in many regions $(18,956$ people) in different age, work and types of behavior.

A share of investors is not so high - 980 investors (about 8 percent). They have opportunity for investment in the US in equities and bonds buying exchange-traded fund. ETF managed autonomously and investors use a buy-and-hold approach: they buy ETF and hold them over extended periods of time.

We created a data set using several criteria like in the research by Lippi et al. (2018). We use statistic tests standard weighted-means analysis ANOVA including $F$-test.

$$
F=\frac{M S_{\text {Treatments }}}{M S_{\text {Error }}}=\frac{S S_{\text {Treatments }} /(I-1)}{M S_{\text {Error }} /\left(n_{T}-I\right)},
$$

where $M S$ is mean square, $I$ is number of treatments and $n_{T}$ is total number of cases to the $F$-distribution with $I-1, T-I$ degrees of freedom. Using the $F$-distribution is a natural candidate, because the test statistic is the ratio of two scaled sums of squares each of which follows a scaled Chi-square distribution. The expected value of $F$ is 1 for no treatment effect. As values of $F$ increase above 1 , the evidence is increasingly inconsistent with the null hypothesis. Two apparent experimental methods of increasing $F$ are increasing the sample size and reducing the error variance by tight experimental controls.

$$
U_{1}=R_{1}-\frac{n_{1}\left(n_{1}+1\right)}{2}
$$

where $n_{1}$ is the sample size for sample 1 , and $R_{1}$ is the sum of the ranks in sample 1 .

First, we only consider investors with different risk sentiment. We have a panel data about for all in- 
vestors: age, field of work, salary, salary stability, income, risk sentiment, savings.

And we find factors that can observe individual risk for ETF investment portfolio.

Second, we form the list of question points for understanding of the individual risk.

Third, we link the question points with the historical ETF performance for last 5 years to understand the historical typical risk for each asset class. This makes it much easier for them to calculate annual risk and potential return.

Finally, we propose algorithm of decision making for optimal asset allocation on the base of our panel data set, consisting of the following stages:

1) answering the list of questions for determining the his own type of investor;

2) selection of criteria for the performance of ETF;

3) analysis of the set of ETF that meet the requirements of the investor;

4) analysis of investment yield time series for the last 5 years;

5) using the optimal allocation in equity and fixed income ETF for his own type of individual investor.

Below we consider the methodology for determining the investor's risk appetite, which consists in getting answers from the investor to 7 questions. It is important to explain before asking each question why it is important to answer a certain question honestly and accurately.

As you know, the investment attractiveness of the object is determined for different types of investors, taking into account their investment preferences and attitude to risk. Each investor has its own system of preferences, based on the purpose of investment and personal characteristics.

A more stable income stream means an increased ability to take risks.
After answering these questions, investors can be clearly classified into several groups. The criteria for choosing the optimal type of ETF will vary depending on the type of ETF (Table 1).

At the same time, the ratio of risk and return is not prevailing in comparison with the level of liquidity risk. The stability of the investor's income depends on the liquidity risk.

When summing up the points for all 7 questions, we get a numerical indicator of the client's riskiness and assign the client to one of 6 risk groups.

Table 1. Points for each answer and level of risk Source: Authors' calculation.

\begin{tabular}{c|c|c|c|c}
\hline Question & $\begin{array}{c}\text { Risk- } \\
\text { averse }\end{array}$ & $\begin{array}{c}\text { Normal risk } \\
\text { sentiment }\end{array}$ & $\begin{array}{c}\text { High risk } \\
\text { sentiment }\end{array}$ & $\begin{array}{c}\text { Very high risk } \\
\text { sentiment }\end{array}$ \\
\hline 1 & 10 & 30 & 70 & 90 \\
\hline 2 & 90 & 10 & 50 & 0 \\
\hline 3 & 50 & 20 & 0 & 0 \\
\hline 4 & 90 & 50 & 20 & 0 \\
\hline 5 & 90 & 70 & 50 & 20 \\
\hline 6 & 30 & 50 & 70 & 0 \\
\hline 7 & 60 & 50 & 20 & 0 \\
\hline
\end{tabular}

Most people consider investing in ETF as an alternative to investing in foreign currency, real estate and bank deposits. Thus, the behavior of investors will differ depending on the selected features.

In our opinion, for individual investors with a passive strategy it is advisable to use one of the following strategies:

1) equity funds and mixed funds have the highest average return on the long-term investment horizon. However, the return on investment depends very much on the talent of the asset manager;

2) if the investment period is up to 1 year, or if the investment horizon is uncertain with moderate expectations of profitability, it is preferable to use a strategy of preservation.

For individual investors, the management strategy depends on market trends:

- in a growing market;

- in a falling market;

- in a neutral market. 
In a growing market, the most appropriate is the use of speculative management strategies. At the same time, an additional advantage will be the availability of insurance against the actions of the management company, that is, certain obligations to maintain the composition of financial instruments in accordance with a certain benchmark.

In a falling market, the most commonly used asset allocation strategy of an ETF is to invest reliable debt instruments and commodity derivatives.

In addition, many investment funds use the strategy of "cash out", that is, sell part of the assets, or completely disband all investment portfolio. But ETFs don't use this strategy.

In a neutral market, speculative trading is the prevailing management strategy.

Since there are always markets with different directions of movement of quotations of financial instruments, there are always opportunities for the implementation of each of these strategies.

Historical average profitability and riskiness are the simplest and most understandable indicators for investors used to assess the allocative efficiency.

The expected allocative efficiency of the ETF is influenced by three groups of factors:

- market returns and other risk factors;

- ETF exposure to these risk factors;

- manager talent.

Various risk-adjusted portfolio management performance indicators have been devised to assess this third factor, which plays the most important role for potential investors, as well as for the management companies themselves that develop compensation schemes for managers.

The results of using this methods are presented in the next section.

\section{RESULTS}

The ability to monitor the market is determined by how well the manager fees the structure of asset allocation depending on the current market conditions. An example of successful market tracking is when a falling market reduces the share of shares in the portfolio and increases the share of bonds.

Table 2 shows descriptive statistics for 979 private investors. We briefly illustrate the share of answers of 7 questions the main in these tables for each individual investor. We have a panel data about for all investors: age, field of work, salary, salary stability, income, risk sentiment, savings.

Investors works in any fields like engineering, military, gas industry, heavy industry, construction, transport, agriculture, control, education, science, culture, health, trading, energy industry, housing and communal services, real estate, social service, jurisprudence, religion, chemical industry, wood industry, sport, information technology, environmental protection, telecommunications, marketing, public organizations.

A field of work and an amount of savings don't influence on individual risk sentiment.

The age of the individuals in the sample varied between 14 and 92 years. On average, the subjects were 44.5 years old. The annual income of the individuals varied between 20,000 and 948,000 USD. The median investor income is 45,059 USD per year. We don't know about average trading portfolio balance.

Table 2. The share of each answer of individual investors in Russia

Source: Authors' calculation.

\begin{tabular}{c|c|c|c|c}
\hline Question & $\begin{array}{c}\text { Risk- } \\
\text { averse }\end{array}$ & $\begin{array}{c}\text { Normal risk } \\
\text { sentiment }\end{array}$ & $\begin{array}{c}\text { High risk } \\
\text { sentiment }\end{array}$ & $\begin{array}{c}\text { Very } \\
\text { high risk } \\
\text { sentiment }\end{array}$ \\
\hline 1 & 27.70 & 15.22 & 51.36 & 5.72 \\
\hline 2 & 55.25 & 31.51 & 13.24 & 0 \\
\hline 3 & 4.18 & 95.82 & 0 & 0 \\
\hline 4 & 17.57 & 33.71 & 48.72 & 0 \\
\hline 5 & 56.34 & 38.65 & 3.99 & 1.02 \\
\hline 6 & 5.02 & 22.42 & 72.57 & 0 \\
\hline 7 & 2.65 & 97.35 & 0 & 0 \\
\hline
\end{tabular}

Table 3 shows descriptive statistics for 979 potential private investors. We have samples for all investors: 1 - age, 2 - salary, 3 - risk sentiment, 4 income, 5 - savings. 
Table 3. ANOVA data summary

Source: Authors' calculation.

\begin{tabular}{|c|c|c|c|c|c|c|c|}
\hline \multirow{2}{*}{ Parameter } & \multicolumn{7}{|c|}{ Samples } \\
\hline & 1 & & 2 & 3 & 4 & 5 & Total \\
\hline$N$ & 978 & & 979 & 979 & 977 & 977 & 4,890 \\
\hline$\Sigma_{X}$ & 200001905 & & 32264796 & 43604 & 9098166 & 22745396 & 264153867 \\
\hline Mean & 204500.925 & & 2956.8907 & 44.5393 & 9312.3501 & 23280.8557 & 54019.1957 \\
\hline$\Sigma_{X^{2}}$ & 199999992 & & 193476959 & 2142474 & 170024521 & 106265331 & 200031666 \\
\hline Variance & 204289648 & & 891024783 & 204.8888 & 87396736.1 & 546230564 & 408854515 \\
\hline Std. dev. & 4519841.23 & & 9850.0382 & 14.3139 & 9348.6222 & 23371.576 & 2022015.12 \\
\hline Std. err. & 144528.585 & & 954.0114 & 0.4575 & 299.0889 & 747.723 & 28915.451 \\
\hline \multicolumn{8}{|c|}{ Standard weighted-means analysis } \\
\hline \multicolumn{8}{|c|}{ ANOVA Summary independent samples $k=5$} \\
\hline $\begin{array}{c}\text { Source } \\
\end{array}$ & SS & $d f$ & MS & $\boldsymbol{F}$ & $P$ & & \\
\hline Treatment [between groups] & 283088020937 & 4 & 707720052344 & 1.73 & 0.140366 & & \\
\hline Error & 199605884680 & 4885 & 408609794637 & & & & \\
\hline
\end{tabular}

But we found just 2 main influence factors for all investors: age and annual income.

We found that risk sentiment is related to age. We use Mann-Whitney U-tests. Sample 1 consists of age of high-risk individuals. Sample 2 consists of age of low-risk individuals. The test indicates that low risk sentiment individuals have lower age (Table 4).
However, we found that risk sentiment is related to income. We use Mann-Whitney U-tests. Sample 1 consists of annual income of high-risk individuals. Sample 2 consists of annual income of low-risk individuals. The test indicates that low-risk sentiment individuals have lower income (Table 5).

We found average risk for investment in Equity ETF \& Fixed Income ETF (Table 6).

Table 4. Mann-Whitney U-test for age factor

\begin{tabular}{|c|c|c|c|}
\hline Result details & Higher risk sentiment & Lower risk sentiment & Combined \\
\hline Sum of ranks & 8,468 & 20,935 & 29,403 \\
\hline Mean of ranks & 206.54 & 104.15 & 121.5 \\
\hline Expected sum of ranks & $4,981.5$ & $24,421.5$ & - \\
\hline U-value & 634 & 7607 & - \\
\hline Expected U-value & $4,120.5$ & $4,120.5$ & - \\
\hline $\begin{array}{l}\text { Standard deviation: } 408.5098 \\
\text { Significance level: } 0.05 \\
\text { The } U \text {-value is } 634 . \\
\text { The } Z \text {-score is }-8.53346 \\
\text { The } p \text {-value is }<0.00001 \\
\text { Result is significant at } p<0.05\end{array}$ & & & \\
\hline
\end{tabular}

Table 5. Mann-Whitney U-test for investment returns factor

Source: Authors' calculation.

\begin{tabular}{|c|c|c|c|}
\hline Result details & Higher risk sentiment & Lower risk sentiment & Combined \\
\hline Sum of ranks & 5,844 & 23,076 & 28,920 \\
\hline Mean of ranks & 142.54 & 115.96 & 120.5 \\
\hline Expected sum of ranks & $4,940.5$ & $23,979.5$ & - \\
\hline U-value & 3,176 & 4,983 & - \\
\hline Expected U-value & $4,079.5$ & $4,079.5$ & - \\
\hline $\begin{array}{l}\text { Standard deviation: } 404.7961 \\
\text { Significance level: } 0.05 \\
\text { The } U \text {-value is } 3176 \text {. } \\
\text { The } Z \text {-score is }-2.23075 \text {. } \\
\text { The } p \text {-value is } 0.02574 \text {. } \\
\text { The result is significant at } p<0.05 \text {. }\end{array}$ & & & \\
\hline
\end{tabular}


Table 6. Asset allocation for each risk profile

Source: Authors' calculation.

\begin{tabular}{l|c|c|c|c}
\multicolumn{1}{c|}{ Name } & Standard deviation, \% & Alpha, \% & Correlation & Average return, \% \\
\hline US Equity ETF & 11.35 & -0.02 & 0.91 & 15.45 \\
US Bond ETF & 4.40 & 0.04 & 0.75 & 2.89 \\
Cryptocurrency (Bitcoin) & 87.76 & 0.35 & 0.15 & 277 \\
\hline
\end{tabular}

Table 7. Asset allocation for each risk profile

\begin{tabular}{|c|c|c|c|c|}
\hline Risk profile & Equity ETF & Fixed income ETF & Cryptocurrency (Bitcoin) & Total \\
\hline 1 & 10 & 90 & 0 & 100 \\
\hline 2 & 34 & 64 & 2 & 100 \\
\hline 3 & 63 & 33 & 4 & 100 \\
\hline 4 & 73 & 22 & 5 & 100 \\
\hline 5 & 87 & 7 & 6 & 100 \\
\hline 6 & 93 & 0 & 7 & 100 \\
\hline
\end{tabular}

Using empirical results about risk sentiment, ETF Thus, market tracking can result in an increase in and cryptocurrency (Bitcoin) risk historical state- the asset allocation beta in a growing market or ment, we can propose optimal asset allocation for a decrease in the asset allocation beta in a falling each type of risk sentiment (Table 6). market.

\section{CONCLUSION}

We found that the risk sentiment is associated with investing in ETF is that ETF profitability fluctuates over time. The stronger these fluctuations in the period under review, the higher the risk. Two groups of factors influence the profitability of asset allocation. The first group is related to general market fluctuations that affect all assets.

Systematic risk is measured by beta ratio of the asset allocation, which measures the sensitivity of the return on asset allocation to the market index.

Most studies use absolute performance indicators that compare the yield of an actively managed asset allocation of ETF and bitcoin with the yield of a passive asset allocation, that is, tied to a specific market index, with the same level of risk.

We found that Russian investors divided for 4 types of risk profiles: risk-averse, normal risk (or rational), high risk, very high risk.

For risk-averse investors, everything is quite simple: you can choose a term deposit in the bank, calculate the final yield in accordance with the terms of the deposit (capitalization, monthly interest accrual, replenishment, etc.), take away from the resulting amount of inflation for the selected period, and all - get the final capital. Thus, if individual puts money in the bank for a year at an average interest rate, most likely, in fact you will not earn anything (or even lose).

Interesting fact: in developed countries, bank deposit rates are usually equal to or below inflation. It turns out that the bank as an investment institution performs only the function of protecting capital from depreciation and no more.

The investment horizon in this financial instrument is from 3 months to 1 year. If you expect a return that at least compensates for the rise in prices, you should turn to risky financial instruments. In this 
case, the shade of your risk profile will also change. This type of investor is willing to accept a minimum level of investment risk, expressed in the possibility of a minor loss of capital (according to various estimates, up to 5 percent), in exchange for the potential to obtain a higher return than from the placement of deposits (8-10 percent in US dollars).

Investment instruments for this type of investor include bonds, structural products with full protection and index instruments for reliable assets.

Normal risk (or rational) investors are ready to accept a reasonable level of investment risk (up to 10 percent according to various estimates) in exchange for a potential opportunity to receive income at the level of 10-13 percent in US dollars. At the same time, the cost of capital may fluctuate, as well as fall below the amount of initial investment in the short term - the so-called drawdown of the portfolio.

A rational investor is a transitional stage between a conservative and an aggressive risk profile. As a rule, a mixed investment portfolio is formed of different instruments with an average ratio. As an example, the portfolio will consist of the most reliable instruments, more or less stable profitable assets, as well as more risky assets.

High risk investor are willing to accept a high level of investment risk and fluctuations in value in the short and medium term in exchange for the potential to generate an average annual return 13-15 percent in US dollars. Moderately aggressive investors may also have a drawdown of the portfolio.

As in the previous type, a mixed investment portfolio is formed, but with a bias in risky assets. If we continue with the example above, the priority in the portfolio will shift towards more exotic markets in the current situation (China, Germany, UK, Australia). Suitable investment products are stocks, commodities and derivatives.

Very high risk investor. This is perhaps the most popularized type of investor - about them movies are shooted, books are written and articles are published. We are ready to accept a high level of investment risk and fluctuations in value in the short and medium term in exchange for a potential opportunity to receive income at the level of 15-17 percent per year in US dollars. The cost of capital can fluctuate and also fall well below the amount of initial investment over a period of time (up to 25 percent of the drawdown). Suitable investment products are stocks, commodities, currencies and derivatives. The investment horizon is at least 3 years. He can independently determine and control the level of investment risk and probable return, but in the case of a number of unsuccessful decisions (transactions), possibly using the leverage and derivative financial instruments, the loss of the speculator may be more than half the amount of its initial investment.

We also found just 2 main influence factors for all potential investors: age and annual income. We found that risk sentiment linked with age of Russian investor: middle-age investor is not so aggressive. The individual risk in young age often become more willing, but older individual investor become less risk-seeking.

Our empirical results confirm (Dwyer et al., 2002) the reversal of the direction of the risk sentiment and age factor in Russia on the back developed countries.

Future research can develop these ideas in the next directions:

1) correlation of risk sentiment and age of investor;

2) correlation of risk sentiment and incomes stability of potential investor in emerging markets. 


\section{REFERENCES}

1. Ackert, L., Charupat, N., Church, B., \& Deaves, R. (2006). An experimental examination of the house money effect in a multiperiod setting. Experimental Economics, 9(1), 5-16. Retrieved from https://link.springer.com/article/10.1007/s10683-006-1467-1

2. Bajtelsmit, V., \& Bernasek, A. (1996). Why do women invest differently than men? Financial Counseling and Planning, 7(1), 1-10. Retrieved from https:// papers.ssrn.com/sol3/papers. cfm?abstract_id $=2238$

3. Barber, B., \& Odean, T. (2000). Trading is hazardous to your wealth: The common stock investment performance of individual investors. Journal of Finance, 55(2), 773-806. Retrieved from https://papers.ssrn.com/sol3/ papers.cfm?abstract_id $=219228$

4. Battalio, R., Kagel, J., \& Jiranyakul, K. (1990). Testing between alternative models of choice under uncertainty: Some initial results. Journal of Risk and Uncertainty, 3(1), 25-50. Retrieved from https://link.springer.com/article/10.1007/BF00213259

5. Bechara, A., Tranel, D., \& Damasio, H. (2000). Characterizations of the decisionmaking deficit of patients with ventromedial prefrontal cortext lesions. Brain, 123(11), 21892202. https://doi.org/10.1093/ brain/123.11.2189

6. Byrnes, J., Miller, D., \& Schafer, W. (1999). Gender differences in risk taking: A meta analysis Psychological Bulletin, 125(3) 367-383. https://psycnet.apa.org/ doi/10.1037/0033-2909.125.3.367

7. Croson, R., \& Gneezy, U. (2009). Gender differences in preferences. Journal of Economic Literature, 47(2), 448-474. http://dx.doi. org/10.1257/jel.47.2.448

8. Dwyer, P. D., Gilkeson, J. H., \& List, J. A. (2002). Gender differences in revealed risk taking: Evidence from mutual fund investors. Economics Letters, 76(2), 151-158. https://doi.org/10.1016/ S0165-1765(02)00045-9
9. Eckel, C., \& Grossman, P. (2008). Forecasting risk attitudes: an experimental study using actual and forecast gamble choices. Journal of Economic Behavior and Organization, 68(1), 1-17. https:// doi.org/10.1016/j.jebo.2008.04.006

10. Franken, I., Georgieva, I., Muris, P., \& Dijksterhuis, A. (2006). The rich get richer and the poor get poorer: On risk aversion in behavioral decision-making. Judgment and Decision Making, 1(2), 153-158. Retrieved from http://journal.sjdm.org/06137/ jdm06137.htm

11. Frino, A., Grant, J., \& Johnstone, D. (2008). The house money effect and local traders on the Sydney Futures Exchange. Pacific-Basin Finance Journal, 16(1-2), 8-25. https://doi.org/10.1016/j.pac fin.2007.04.002

12. Halek, M., \& Eisenhauer, J. G (2001). Demography of risk aversion. The Journal of Risk and Insurance, 68(1), 1-24. https://doi. org/10.2307/2678130

13. Hartog, J., Ferrer-1-Carbonell, A., \& Jonker, N. (2002). Linking measured risk aversion to individual characteristic. Kyklos, 55(1), 3-26. https://doi. org/10.1111/1467-6435.00175

14. Hsu, Y. L., \& Chow, E. (2013). The house money effect on investment risk taking: Evidence from Taiwan. Pacific-Basin Finance Journal, 21(1), 1102-1115. https://doi. org/10.1016/j.pacfin.2012.08.005

15. Imas, A. (2016). The realization effect: Risk-taking after realized versus paper losses. American Economic Review, 106(8), 20862109. Retrieved from https://www. aeaweb.org/articles?id=10.1257/ aer.20140386

16. Kahneman, D., \& Tversky, A. (1979). Prospect theory: An analysis of decision under risk. Econometrica, 47(2), 263-292. https://doi.org/10.2307/1914185

17. Keasey, K., \& Moon, P. (1996). Gambling with the house money in capital expenditure decisions: An experimental analysis. Economics Letters, 50(1), 105-110. https://doi.org/10.1016/01651765(95)00726-1

18. Lippi, A., Barbieri, L., Piva, M., \& De Bondt, W. (2018). Timevarying risk behavior and prior investment outcomes: Evidence from Italy. Judgment and Decision Making, 13(5), 471-483. Retrieved from https://ideas.repec.org/a/ jdm/journl/v13y2018i5p471-483. html

19. Liu, Y.-J., Tsai, C.-L., Wang, M.-C., \& Zhu, N. (2010). Prior consequences and subsequent ris taking: New field evidence from the Taiwan Futures Exchange. Management Science, 56(4), 606-620. https://doi.org/10.1287/ mnsc. 1090.1131

20. Lusardi, A., \& Mitchell, O. (2008) Planning and financial literacy: How do women fare? American Economic Review, 98(2), 413-417. https://doi.org/10.3386/w13750

21. Merkle, C. (2017). Financial overconfidence over time: Foresight, hindsight, and insight of investors. Journal of Banking \& Finance, 84, 68-87. https://doi.org/10.1016/j.jbankfin.2017.07.009

22. Mikhailov, A. (2018). Pricing in Oil Market and Using Probit Model for Analysis of Stock Market Effects. International Journal of Energy Economics and Policy, 4, 43-53. Retrieved from http://www.econjournals.com/ index.php/ijeep/article/view/5846

23. Mikhaylov, A. (2018). Volatility Spillover Effect between Stock and Exchange Rate in Oil Exporting Countries. International Journal of Energy Economics and Policy, 8(3), 321-326. Retrieved from https:// www.econjournals.com/index. php/ijeep/article/view/6307

24. Nosić, A., \& Weber, M. (2010). How riskily do I invest? The role of risk attitudes, risk perceptions, and overconfidence. Decision Analysis, 7(3), 282-301. https://doi. org/10.1287/deca.1100.0178

25. Powell, M., \& Ansic, D. (1997). Gender differences in risk behaviour in financial decisionmaking. An experimental 
analysis. Journal of Economic

Psychology, 18(6), 605-628.

https://doi.org/10.1016/S0167-

4870(97)00026-3

26. Riley, W. B., \& Chow, K. V. (1992) Asset allocation and individual risk aversion. Financial Analysts Journal, 48(6), 32-37. Retrieved from https://www.jstor.org/ stable/4479593?seq=1\#page_scan_ tab_contents

27. Schubert, R., Brown, M., Gysler, M., \& Brachinger, H. (1999). Financial decision-making: Are women really more riskaverse? American Economic Review, 89(2), 381-385. Retrieved from https://www.jstor.org/ stable/117140?seq=1\#page_scan_ tab_contents
28. Shiv, B., Loewenstein, G., \& Bechara, A. (2005). The dark side of emotion in decision-making: When individuals with decreased emotional reactions make more advantageous decision. Cognitive Brain Research, 23(1), 85-92. https://doi.org/10.1016/j.cogbrainres.2005.01.006

29. Thaler, R. H., \& Johnson, E. J. (1990). Gambling with the house money and trying to break even: Effects of prior outcomes on risky choice. Management Science, 36(6), 643-660. Retrieved from https://www.jstor.org/ stable/2631898?seq=1\#page_scan_ tab_contents

30. Tversky, A., \& Kahneman, D. (1981). The framing of decisions and the psychology of choice. Science, 211(4481), 453-458. https://doi.org/10.1126/science. 7455683

31. Tversky, A., \& Kahneman, D. (1992). Advances in prospect theory: Cumulative representation of uncertainty. Journal of Risk and Uncertainty 5(4), 297-323. Retrieved from https://link.springer.com/article/10.1007/BF00122574

32. Weber, M., \& Zuchel, H. (2005) How do prior outcomes affect risk attitude? Comparing escalation of commitment and house-money effect. Decision Analysis, 2(1), 30-43. https://doi. org/10.1287/deca.1050.0034

\section{APPENDIX}

\section{LIST OF QUESTIONS:}

1. Global financial markets can be very volatile. If your investment portfolio lost 10 percent of its value in a month during a market crash, what would you do?

A. I would sell all tools.

B. I would sell some of the tools.

C. I would keep portfolio unchanged.

D. I would buy a larger volume.

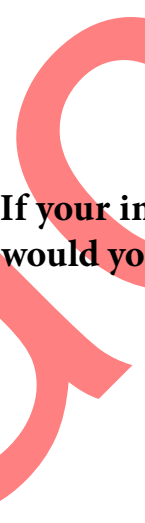

This question assesses your tolerance for loss. The greater your tolerance, the greater the risk you are willing to take. Risk willingness and ability to take risks is important when choosing ETF.

\section{When deciding how to invest your money, do you care about the most?}

\section{A. Profit maximization.}

B. Loss minimization.

C. With and about how and other.

Taking care more about maximizing profits requires a greater willingness to take risks than seeking to minimize losses.

\section{Do you have any other financial instruments that have a significant value?}

A. Yes.

B. No.

People who have experience or own any financial instruments are usually willing to take more risk on their investments. 


\section{What is your current age?}

A. $18-30$ years.

B. $30-50$ years.

C. Over 50 years of age.

The closer you are to retirement age, the less risk you are generally willing to take, as your savings will ultimately create your retirement income.

\section{What is the total amount of your cash and liquid investments at the moment?}
A. Less than 20,000 USD.
B. 20,000-50,000 USD.
C. 50,000-100,000 USD.
D. More than 100,000 USD.

We use the current value of your savings to estimate your retirement income and compare it with your estimates of post-retirement spending needs. If your projected retirement income exceeds your projected spending, you have the opportunity to take greater risks.

\section{What is your annual income after taxes?}
A. Less than 10,000 USD.
B. 10,000-20,000 USD.
C. More 20,000 USD.

We use your current salary to determine the amount of your savings, which plays an important role in predicting your pension. You have the option to take a greater risk if your projected retirement income exceeds your pension spending needs.

7. How stable is your current and future earnings? (for example, wages, social security, pensions, interest, rental income

A. Stable (unlikely to decrease).

B. Quite stable.

C. Unstable. 